\title{
P05.65. BHIP - be healthy in pregnancy: strategies nutritional and physical activity interventions to improve gestational weight gain management
}

\author{
R Walji, S Atkinson, O Wahoush \\ From International Research Congress on Integrative Medicine and Health 2012 \\ Portland, Oregon, USA. 15-18 May 2012
}

\section{Purpose}

Excess gestational weight gain (GWG) in pregnancy is a major clinical challenge affecting 55-75\% of Canadian women who enter pregnancy overweight and about $40 \%$ women of normal weight. The adverse sequelae of excess GWG for both mother and child are well documented and include a number of adverse health outcomes (such as gestational diabetes, hypertension and preeclampsia), which impose substantive burden of our health system. The larger research program aims to conduct a randomized trial with a diet and exercise intervention for optimizing GWG. The project presented here is a preliminary phase in order to determine feasibility and patient preferences to the proposed intervention.

\section{Methods}

This project uses a qualitative approach employing focus groups and interviews of participant women (pregnant or recently pregnant) and health care providers that aims to identify the preferred evidence-based strategies for women to effectively manage their GWG during and after pregnancy and how best to implement the selected intervention. Primary research question: What are the preferences of pregnant and post-partum women and their health providers for engaging in healthy eating and increased physical activity? Secondary questions include: What do pregnant or recently pregnant women and health providers identify as enablers or barriers that support or limit successful management of GWG? What are women's and health providers' perceptions of GWG in relation to their health and the health of the child?

McMaster University, Hamilton, Ontario, Canada
What approaches have women and health providers tried to manage excess GWG?

\section{Results}

Outcomes include an identified preferred diet and exercise intervention for the planned clinical trial and information, which enables refinement of a locally acceptable implementation plan for the intervention.

\section{Conclusion}

Collectively information from women and service providers enabled a comprehensive understanding of barriers, enablers and opportunities for the successful implementation of an intervention for GWG management.

Published: 12 June 2012

\section{doi:10.1186/1472-6882-12-S1-P425}

Cite this article as: Walji et al:: P05.65. BHIP - be healthy in pregnancy:

strategies nutritional and physical activity interventions to improve

gestational weight gain management. BMC Complementary and

Alternative Medicine 2012 12(Suppl 1):P425.

Submit your next manuscript to BioMed Central and take full advantage of:

- Convenient online submission

- Thorough peer review

- No space constraints or color figure charges

- Immediate publication on acceptance

- Inclusion in PubMed, CAS, Scopus and Google Scholar

- Research which is freely available for redistribution

(c) 2012 Walji et al; licensee BioMed Central Ltd. This is an Open Access article distributed under the terms of the Creative Commons 